and the modern Kessler plants, are described in full detail, with excellent working drawings and reproductions of photographs of actual plant. The condensation of fumes, a most important part of the operation of a concentration plant, is discussed, and the Cottrell and Calder-Fox systems described. The recovery of waste acid and the transport of acid are also included.

Mr. Parkes's revision has been thorough, and his book is a complete treatise on the theory and practice of the concentration of sulphuric acid.

J. R. P.

\section{Psychology as a Science.}

The Nature of Intelligence. By Prof. L. L. Thurstone. (International Library of Psychology, Philosophy and Scientific Method.) Pp. xvi+ r67. (London: Kegan Paul and Co., Ltd.; New York: Harcourt, Brace and Co. Inc., I924.) Ios. $6 d$. net.

T HE fact which is, perhaps, most obvious to readers of psychological literature is that each School uses language which is entirely unmeaning when applied to another School ; the behaviourist, the experimentalist, the psychiatrist, and the academic psychologist all appear to be talking in different languages, and Prof. Thurstone attempts both to unravel the reasons of the medley and also to construct an intelligible science out of it. His book is thus the first real attempt to bring into a composite whole the different branches of psychology and, for that reason alone, commends itself to all serious students.

Prof. Thurstone finds the chief reason of the differences to be that the specialists lay stress on diverse entities in conduct; they look at the subject from entirely dissimilar points of view, and (in the author's view), wrongly, build up a science which is not really true to the facts. Thus the behaviourist stresses "overt conduct," the experimentalist mere stimulus and response, the academician "consciousness and its states," and the psychiatrist abnormal psychology. The author, however, would combine the different points of view and, by shifting the stress of the special branches, construct a science at once more human and accurate.

Our author begins by showing how the stimulusresponse theory must give way to the theory that impulses generate in the organism and only use stimuli in so far as they are able to satisfy the feeling generated by the activity. He then goes on to show that consciousness is an evolutionary development the sole use of which is that it leads to activity and thereby helps to gain the object desired. But this is not enough. After consciousness and its states we must have the overt act, the behaviour of the organism in order to complete the cycle. Thus a complete view of psychology begins with the "energy-source" in the individual, passes through consciousness by means of ideation to the external stimuli, proceeds to the overt act, and ends with the satisfaction of the impulse and the quiescence of the "energy-source." Looked at from this basis, intelligent conduct depends upon whether it is possible for the individual to focus in consciousness at an early stage of the impulse the specific universal meaning of the impulse and thereby make use of " trial and error" conduct. Grades of intelligence are grades of powers of inhibition, powers, that is, effectively to control mere reflex actions in order better to satisfy the impulse.

We cannot enter into details of the book. It is doubtful whether Prof. Thurstone really means the phrase "consciousness is unfinished conduct"; if he does, then he is severely limiting the use of the word "consciousness" and his definitions, both of consciousness and intelligence, appear to savour of descriptions, and, at any rate, are both debatable. The book, however, is simply written and is illuminated by profuse and clear diagrams, and his theory is backed up by a wealth of good psychological examples. It should be read, if only as a stimulus to thought and to give a clear view of the real need for a science which will combine the different branches of psychology.

\section{Cotton in Australia.}

Cotton in Australia: the Possibilities and the Limitations of Australia as a Cotton-growing Country. By Richard Harding. Pp. xviii +27 . (London: Longmans, Green and Co., I924.) I2s. $6 d$. net.

THE author describes this book as the result of eighteen months' investigation made in Australia, when secretary of the British Cotton Delegation, I922. He sets out to prove that great areas of that continent can produce cotton commercially; of course he succeeds. At first one is inclined to resent the facile optimism of the fourth chapter, which is especially devoted to this proof, where the author openly omits a drought year from his averages and guesses the available resources in six significant figures ; but having duly discounted his rather uncritical attitude, we can welcome this book as the first available general statement of the Australian cotton position. That the country has large potential cotton areas is clear; the Government proposes to face the basic difficulty of getting labour for the picking season (from white men in a cottongrowing climate) by planting many small areas, each on one man's small holding. Whether the plan will work remains to be seen, but Mr. Harding certainly puts his finger on two essentials; one is the cultivation of a big boll type, since the labour of picking a given weight of crop is almost inversely proportional to the boll weight; the other is the advisability of insisting 